\title{
Negative synergy of mental disorders and oral diseases versus general health
}

\section{Efekt negatywnej synergii zaburzeń psychicznych i chorób jamy ustnej w odniesieniu do zdrowia ogólnego}

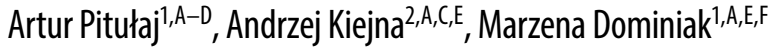 \\ ${ }^{1}$ Department of Dental Surgery, Faculty of Dentistry, Wroclaw Medical University, Poland \\ ${ }^{2}$ Psychology Research Unit for Public Health, University of Lower Silesia, Wrocław, Poland \\ A - research concept and design; $\mathrm{B}$ - collection and/or assembly of data; $\mathrm{C}$ - data analysis and interpretation; \\ $D$ - writing the article; $\mathrm{E}$ - critical revision of the article; $\mathrm{F}$ - final approval of the article
}

Address for correspondence

Artur Pitułaj

E-mail: arturpitulaj@gmail.com

Funding sources

None declared

Conflict of interest

None declared

Received on January 27, 2019

Reviewed on February 10, 2019

Accepted on March 4, 2019

Published online on May 10, 2019

\begin{abstract}
In recent years, the World Health Organization (WHO) has undertaken wide-ranging epidemiological research with the purpose of discovering and confirming correlations between mental disorders and somatic diseases. Despite strong evidence for the existence of a two-way dependence between psychological disorders and general diseases, interest in studying the similar impact of oral health is still low. The purpose of this paper was to investigate the multidirectional dependencies between mental, oral and somatic health, and the importance of an interdisciplinary approach to each psychiatric patient.

The PubMed, MEDLINE, Web of Science, and Google Scholar databases were searched for articles published between 1994 and 2018 which involved studies examining the interdependencies between oral, general and mental health, using the following keywords: "comorbidities", "common mental disorders", "mental health", "oral health", "depression", "periodontitis", and "WHO". This review highlights the fact that there is still limited discussion on the importance of the impact of oral health on the general health of psychiatric patients. Data gathered in this paper suggests that an oral examination of mentally ill patients should be considered mandatory.
\end{abstract}

Key words: mental health, oral health, World Health Organization, interdisciplinary approach

Słowa kluczowe: zdrowie psychiczne, zdrowie jamy ustnej, Światowa Organizacja Zdrowia, podejście interdyscyplinarne
Cite as

Pitułaj A, Kiejna A, Dominiak M. Negative synergy of mental disorders and oral diseases versus general health. Dent Med Probl. 2019;56(2):197-201. doi:10.17219/dmp/105253

D0I

$10.17219 / \mathrm{dmp} / 105253$

Copyright

๑ 2019 by Wroclaw Medical University

This is an article distributed under the terms of the

Creative Commons Attribution 3.0 Unported License (CC BY 3.0)

(https://creativecommons.org/licenses/by/3.0/) 


\section{Introduction}

Mental disorders are considered to be a vital component of the global burden of illnesses worldwide. They are proven to have a significant influence on constricting the physical fitness, increasing the rate of death and exacerbating other chronic diseases. ${ }^{1}$ Neuropsychiatric diseases, including depression, bipolar disorder, schizophrenia, anxiety disorders, or developmental delays, apart from being the cause of disability on a global scale, are also responsible for reducing life expectancy. ${ }^{2}$ According to the statistics, 1 in 6 people show the characteristics of common mental health disorders (CMD), and half of them present symptoms which justify intervention from health service employees. ${ }^{3}$

Every year, new dependencies are discovered between mental disorders, oral cavity health and general diseases. The aim of the following article was to analyze current activity in the literature and to present information regarding the potential influence of mental diseases on the condition of the oral cavity from the perspective of oral medicine and general medicine (Fig. 1).

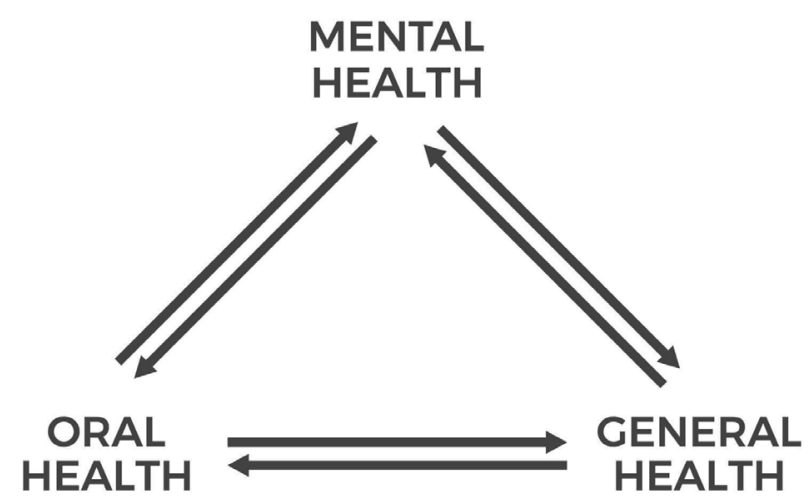

Fig. 1. Relationships between mental, oral and general health

\section{Mental disorders and the World Health Organization initiative}

Due to the significance of mental disorders and difficulty in diagnosing them, in 2000, the World Health Organization (WHO) created the World Mental Health Survey Initiative (WMH-SI), aiming to collect detailed data from around the world on the frequency of occurrence and the correlation of mental disorders, conduct disorders and the use of psychoactive substances. ${ }^{4}$ The WMH-SI consortium consists of a representative study on a national and regional scale in 27 countries, representing all parts of the world. The final sample exceeds 144,000 interviews, according to the data from 2015 (https://www.hcp.med. harvard.edu/wmh/).
The data collection is based on factually unified interviews performed by qualified pollsters with no clinical experience. All surveys use the same Composite International Diagnostic Interview (CIDI), designed by WHO, which assures the compatibility of the data collected worldwide. ${ }^{5}$ The CIDI questionnaire is a multilevel screening module which evaluates diagnosis, performance, treatment, risk factors, socio-demographic correlations, and methodological factors. It also includes questions concerning somatic illnesses diagnosed by a doctor. Computer-generated diagnosis is assisted by definitions and criteria based on the $4^{\text {th }}$ edition of the Diagnostic and Statistical Manual of Mental Disorders (DSM-IV) and the $10^{\text {th }}$ revision of the International Statistical Classification of Diseases and Related Health Problems (ICD-10). ${ }^{6}$

\section{Mental health and somatic health}

The WMH-SI demonstrated the influence of mental disorders on the prevalence of many general diseases. For instance, anxiety disorders, depression, intermittent explosive disorders, and medication and alcohol abuse were linked with increased rates of future peptic ulcer disease, diagnosis of hypertension and heart diseases. ${ }^{7-9}$ A general association was observed between the prevalence of mental disorders and an increase in the probability of cancer after they occurred. Depression was more strongly connected with independently reported tumors detected at the early stages of life, and with women. Post-traumatic stress disorder (PTSD) was also connected with the occurrence of tumors detected at the early stages of life. ${ }^{10}$ Depression and impulse control disorders (especially eating disorders) correlated with an increase in the incidence of diabetes. ${ }^{11}$ The findings of the analysis indicate a connection between these two states - mental and somatic - and support arguments in favor of the early detection and treatment of mental disorders. The data emphasizes the importance of monitoring the physical health of people with such illnesses.

\section{Mental and oral cavity wellness}

Oral cavity diseases, including tooth decay, have a negative impact on quality of life among children and adults. Dysfunction of the masticatory apparatus translates into lingering discomfort and difficulties in one's social life. ${ }^{12}$ Kisely indicated a two-way association between oral health and mental health. ${ }^{13}$ It is assumed that at least half of dental patients feel anxiety before going to a dentist and some of them develop anxiety disorders - dentophobia, for instance. ${ }^{13,14}$ In spite of the existing evidence of the poor oral cavity health of people suffering from mental disorders, that association is still marginalized. 
Chronic periodontitis has been recognized as an independent factor of an increased risk of depression. ${ }^{15}$ Among adult patients suffering from at least 1 mental disorder, there is a twofold increase in the risk of encountering dental defects that require treatment. ${ }^{16}$

People with diagnosed anxiety disorders or depression use dental services considerably less frequently, and are more prone to tooth loss than mentally healthy people, by about $30 \%{ }^{13,17}$ Observed changes in behavior include a gradually increasing indifference toward their own state of wellness, changes in eating habits, leading to increased consumption of foods rich in carbohydrates, and brushing teeth less often, behavior which conduces to the development of dental caries, periodontal diseases and tooth loss. ${ }^{18-20}$ Chronic stress, anxiety and symptoms of depression are connected with a reduction in the amount of saliva produced and a feeling of oral cavity dryness. ${ }^{21}$ Drying of the mucous membrane renders it vulnerable to injuries and hinders self-cleaning of the tooth surfaces and of the periodontium.

Anxiety disorders and depression are notable risk factors of parafunctional activity, especially bruxism. It leads to temporomandibular joint disorders (TMDs), tooth abrasion and overextension, and subsequent loosening of teeth. ${ }^{22}$ The inability to chew properly, arthralgia and speaking problems are the causes of both biological and interpersonal dysfunctions that affect one's mental state. Due to the multidirectional relationship between TMDs and mental health, it is often difficult to assess whether TMDs are the cause or the effect of mental disorders. ${ }^{23}$ Moreover, the intense pain associated with arthralgia, caused by muscular disorders, in patients who also suffer from psychosomatic pathologies, is known to notably worsen oral health-related quality of life. ${ }^{24}$ Parafunctions are also responsible for premature injuries of fixed and mobile prosthetic fillings, due to their occlusal overextension, which impedes the effective rehabilitation of patients in need of prosthetic restorations. ${ }^{25}$ The manner of pharmacological treatment of patients with mental disorders may intensify any adverse behavior and may pose a risk of oral cavity diseases, mainly escalating the dryness of the mucous membrane. ${ }^{16,26}$ The side effects of such medication also include inflammation of the saliva glands, gums and the mucous membrane of the oral cavity. Moreover, drugs categorized as selective serotonin reuptake inhibitors (SSRIs) may escalate bruxism, while long-term usage of heterocyclic compounds may increase tooth decay due to an increased craving for sweets. ${ }^{27}$

\section{Oral cavity health and somatic diseases}

Periodontitis is a chronic bacterial disease which leads to the damage of the structures holding the teeth in the alveolus, like the gingiva, alveolar process and periodontal fibers. The pathogenesis of this particular disease includes chronic inflammation states, which change the balance between many systems, including the nervous, immune and hormonal systems. ${ }^{28}$ There is ample evidence that existing periodontal disease affects the incidence and exacerbation of numerous systemic diseases. The most commonly described ones include diabetes, osteoporosis, respiratory system diseases, rheumatic diseases, obesity, erectile dysfunction, kidney problems, dementia, some malignant tumors, and cardiovascular diseases - primarily atherosclerosis and its complications. ${ }^{29-32}$

The development of periodontitis is dependent upon a specific vulnerability and the presence of bacterial dysbiotic microflora. ${ }^{33}$ According to Socransky, Porphyromonas gingivalis, Tannerella forsythia and Treponema denticola belong to the red complex and are most commonly detected in the areas altered by the disease. ${ }^{\text {acc.34 }}$ However, Porphyromonas gingivalis is considered the primary bacterium which determines the beginning of periodontitis; this microbe is able to disturb the physiological balance between the bacteria inhabiting the oral cavity and the immune response of the host on a molecular level. ${ }^{35}$ Porphyromonas gingivalis demonstrates the ability to spread throughout the body through bacteremia, causing distant infections and the exacerbation of existing diseases. The bacteria have the ability to penetrate the circulatory system through the epithelial surface altered by inflammation. Inhabiting and proliferating on the blood vessel endothelium surfaces, it initiates the process of atherosclerosis. Its DNA may be found on the atherosclerosis-affected plaques in the coronary vessels of people who died of cardiac arrest. ${ }^{36}$ A high amount of Porphyromonas gingivalis in the periodontal pockets of pregnant women, or its presence in the amniotic fluid or on the surface of the placenta, increases the risk of premature birth, which in turn constitutes a major cause of death for infants. ${ }^{37}$ Tooth loss due to tooth decay and periodontitis is a vital factor in the occurrence of many malignant tumors, including cancer of the head and neck areas, or of the esophagus and stomach. ${ }^{38-40}$

\section{Summary}

Despite the major significance of mental disorders as a global health concern, their occurrence along with other comorbidities, and the possible cause-effect links between them and the most commonly occurring general diseases, they still have not been thoroughly researched. Only in recent years, due to the concerns of $\mathrm{WHO}$, has wide-ranging epidemiological research aimed at discovering and confirming such correlations been undertaken. Kisely's insight shed light on the existing undisputed correlation and interaction between mental health and oral health. Although oral cavity diseases are vitally relevant to physical health, they are closely related to the occurrence and course of chronic somatic diseases which are frequently encountered in psychiatric patients. ${ }^{13}$ 
This argument and the adverse effects of mental disorders on the medical condition of the oral cavity suggest the need for increased attention and dental care in this group of patients.

The epidemiological research connected with CIDI, in relation to the somatic medical status, is based on the information about the health of the people surveyed, not on medical examinations. Broadly speaking, this may result in the collected data being imprecise, for a variety of reasons. However, most people undergo periodic health examinations, ensuring that they possess at least some general knowledge about their illnesses and overall medical condition. Using the information gleaned from a doctor, they answer the questions in epidemiological questionnaires like CIDI. Regrettably, elements of oral cavity health are often omitted from the survey. ${ }^{41}$ In many countries, there are free preventative programs for examining children's dentition. However, adult patients are required to buy insurance or to pay for the examination, which in some parts of the world significantly decreases the availability of dental services, and consequently decreases the awareness of the oral medical condition. ${ }^{42,43}$ There is also a tendency that, with age, the frequency of regular dental health examinations is reduced. ${ }^{44}$

Therefore, it is vital to collect the broadest possible scope of information concerning the magnitude and the types of dental health issues, e.g., by adding relevant questions to the main part of large epidemiological questionnaires like CIDI. This addition could facilitate the identification of further correlations between mental health and oral health. Moreover, dental problems such as halitosis, bleeding gums, pain, bruxism, tooth loosening, or tooth loss are easily recognized by patients, and provide an important and readily available source of supplementary information on the health status of the people surveyed.

The existing evidence for the multidirectional dependencies between oral, mental and somatic health disorders highlight the need for a broad view of each patient. A comprehensive examination of an individual, often exceeding the scope of knowledge of a single specialist, leads to effective preventative and curative treatment.

\section{Conclusions}

There are multidirectional dependencies between mental disorders, oral health and general health. Psychiatric patients require special dental care, as they have a considerably higher risk of general diseases, including exacerbated secondary ones, because of the often poor condition of their oral cavity. An oral examination of people suffering from mental disorders should be considered mandatory. Adding the right questions about oral health to the general part of mental health diagnostic questionnaires would help to further study the relationship between mental health and the diseases of the stomatognathic system.

\section{ORCID iDs}

Artur Pitułaj (1) https://orcid.org/0000-0002-9025-2628

Andrzej Kiejna (1) https://orcid.org/0000-0002-3708-3853

Marzena Dominiak (1) https://orcid.org/0000-0001-8943-0549

\section{References}

1. Prince M, Patel V, Saxena S, et al. No health without mental health. Lancet. 2007;370(9590):859-877.

2. Lopez AD, Mathers CD, Ezzati M, Jamison DT, Murray CJL, eds. Global Burden of Disease and Risk Factors. Washington, DC: The International Bank for Reconstruction and Development / The World Bank; New York, NY: Oxford University Press; 2006.

3. Common mental health disorders (National Institute for Heath and Care Excellence (NICE) clinical guideline 123). In: National Collaborating Centre for Mental Health (UK). Common Mental Health Disorders: Identification and Pathways to Care. Leicester, UK: British Psychological Society; 2011. https://www.ncbi.nlm.nih.gov/books/NBK92254/

4. Demyttenaere K, Bruffaerts R, Posada-Villa J, et al.; WHO World Mental Health Survey Consortium. Prevalence, severity and unmet need for treatment of mental disorders in the World Health Organization World Mental Health Surveys. JAMA. 2004;291(21):2581-2590.

5. Kessler RC, Aguilar-Gaxiola S, Alonso J, et al. The global burden of mental disorders: An update from the WHO World Mental Health (WMH) surveys. Epidemiol Psichiatr Soc. 2009;18(1):23-33.

6. Kessler RC, Ustün TB. The World Mental Health (WMH) survey initiative version of the World Health Organization (WHO) Composite International Diagnostic Interview (CIDI). Int J Methods Psychiatr Res. 2004;13(2):93-121.

7. Scott KM, Alonso J, de Jonge P, et al. Associations between DSM-IV mental disorders and onset of self-reported peptic ulcer in the World Mental Health Surveys. J Psychosom Res. 2013;75(2):121-127.

8. Stein DJ, Aguilar-Gaxiola S, Alonso J, et al. Associations between mental disorders and subsequent onset of hypertension. Gen Hosp Psych. 2014;36(2):142-149.

9. Scott KM, de Jonge P, Alonso J, et al. Associations between DSM-IV mental disorders and subsequent heart disease onset: Beyond depression. Int J Cardiol. 2013;168(6):5293-5299.

10. O'Neill S, Posada-Villa J, Medina-Mora ME, et al. Associations between DSM-IV mental disorders and subsequent self-reported diagnosis of cancer. J Psychosom Res. 2014;76(3):207-212.

11. De Jonge P, Alonso J, Stein DJ, et al. Associations between DSM-IV mental disorders and diabetes mellitus: A role for impulse control disorders and depression. Diabetologia. 2014;57(4):699-709.

12. Dimberg L, Arnrup K, Bondemark L. The impact of malocclusion on the quality of life among children and adolescents: A systematic review of quantitative studies. Eur J Orthod. 2015;37(3):238-247.

13. Kisely S. No mental health without oral health. Can J Psychiatry. 2016;61(5):277-282.

14. Cormac I, Jenkins $P$. Understanding the importance of oral health in psychiatric patients. Adv Psychiatr Treat. 1999;5(1):53-60.

15. Hsu CC, Hsu YC, Chen HJ, et al. Association of periodontitis and subsequent depression: A nationwide population-based study. Medicine (Baltimore). 2015;94(51):e2347.

16. Heaton LJ, Swigart K, McNelis G, Milgrom P, Downing DF. Oral health in patients taking psychotropic medications: Results from a pharmacybased pilot study. J Am Pharm Assoc. 2016;56(4):412-417.e1.

17. Okoro CA, Strine TW, Eke PI, Dhingra SS, Balluz LS. The association between depression and anxiety and use of oral health services and tooth loss. Community Dent Oral Epidemiol. 2012;40(2):134-144.

18. D'Avila OP, Wendland E, Hilgert JB, Padilha DMP, Hugo FN. Association between root caries and depressive symptoms among elders in Carlos Barbosa, RS, Brazil. Braz Dent J. 2017;28(2):234-240.

19. Wallin MS, Rissanen AM. Food and mood: Relationship between serotonin and affective disorders. Acta Psychiatr Scand. 1994;377(Suppl):36-40.

20. Anttila S, Knuuttila M, Ylöstalo $P$, Joukamaa M. Symptoms of depression and anxiety in relation to dental health behavior and self-perceived dental treatment need. Eur J Oral Sci. 2006;114(2):109-114.

21. Gholami N, Sabzvari BH, Razzaghi A, Salah S. Effect of stress, anxiety and depression on unstimulated salivary flow rate and xerostomia. J Dent Res Dent Clin Dent Prospect.2017;11(4):247-252. 
22. Lobbezoo F, Van Der Zaag J, Naeije M. Bruxism: Its multiple causes and its effects on dental implants - an updated review. J Oral Rehabil. 2006;33(4):293-300.

23. Berger M, Oleszek-Listopad J, Marczak M, Szymańska J. Psychological aspects of temporomandibular disorders - literature review. Curr Issues Pharm Med Sci. 2015;28(1):55-59.

24. Blanco-Aguilera A, Blanco-Aguilera E, Serrano-del-Rosal R, et al. Influence of clinical and psychological variables upon the oral health-related quality of life in patients with temporomandibular disorders. Med Oral Patol Oral Cir Bucal. 2017;22(6):e669-e678.

25. Alharby A, Alzayer $\mathrm{H}$, Almahlawi $A$, et al. Parafunctional behaviors and its effect on dental bridges. J Clin Med Res. 2018;10(2):73-76.

26. Friedlander AH, Mahler ME. Major depressive disorder: Psychopathology, medical management and dental implications. J Am Dent Assoc. 2001;132(5):629-638.

27. Friedlander AH, Friedlander IK, Gallas M, Velasco E. Late-life depression: Its oral health significance. Int Dent J. 2003;53(1):41-50.

28. Rettori E, De Laurentiis A, Dees WL, Endruhn A, Rettori V. Host neuro-immuno-endocrine responses in periodontal disease. Curr Pharm Des. 2014;20(29):4749-4759.

29. Otomo-Corgel J, Pucher JJ, Rethman MP, Reynolds MA. State of the science: Chronic periodontitis and systemic health. J Evid Based Dent Pract. 2012;12(Suppl 3):20-28.

30. Gomes-Filho IS, das Mercês MC, de Santana Passos-Soares J, et al Severity of periodontitis and metabolic syndrome: Is there an association? J Periodontol. 2016;87(4):357-366.

31. Kozarov EV, Dorn BR, Shelburne CE, Dunn WA Jr, Progulske-Fox A HumanatheroscleroticplaquecontainsviableinvasiveActinobacillus actinomycetemcomitans and Porphyromonas gingivalis. Arterioscler Thromb Vasc Biol. 2005;25(3):e17-e18.

32. Suresh S, Mahendra J. Multifactorial relationship of obesity and periodontal disease. J Clin Diagn Res. 2014;8(4):ZE01-ZE3.

33. Demoersman J, Pochard P, Framery C, et al. B cell subset distribution is altered in patients with severe periodontitis. PLoS One. 2018;13(2):e0192986.

34. Holt SC, Ebersole JL. Porphyromonas gingivalis, Treponema denticola, and Tannerella forsythia: The "red complex", a prototype polybacterial pathogenic consortium in periodontitis. Periodontol 2000. 2005;38:72-122.

35. Tribble GD, Kerr JE, Wang B-Y. Genetic diversity in the oral pathogen Porphyromonas gingivalis: Molecular mechanisms and biological consequences. Future Microbiol. 2013;8(5):607-620.

36. Xu W, Pan Y, Xu Q, et al. Porphyromonas gingivalis ATCC 33277 promotes intercellular adhesion molecule-1 expression in endothelial cells and monocyte-endothelial cell adhesion through macrophage migration inhibitory factor. BMC Microbiol. 2018;18(1):16.

37. Miyauchi M, Ao M, Furusho H, et al. Galectin-3 plays an important role in preterm birth caused by dental infection of Porphyromonas gingivalis. Sci Rep. 2018;8(1):2867.

38. Zeng X-T, Luo W, Huang W, Wang Q, Guo Y, Leng WD. Tooth loss and head and neck cancer: A meta-analysis of observational studies. PLoS One. 2013;8(11):e79074.

39. Wang Y, Peng J, Li Y, et al. Association between tooth loss and risk of oesophageal cancer: A dose-response meta-analysis. Springerplus. 2016;5(1):1020.

40. Yin $\mathrm{XH}$, Wang YD, Luo $\mathrm{H}$, et al. Association between tooth loss and gastric cancer: A meta-analysis of observational studies. PLoS One. 2016;11(3):e0149653.

41. Milone SD, Lopes Milone S. Evidence-based periodic health examination of adults. Memory aid for primary care physicians. Can Fam Physician. 2006;52(1):40-47.

42. Huebner CE, Chi DL, Masterson E, Milgrom P. Preventive dental health care experiences of preschool-age children with special health care needs. Spec Care Dentist. 2015;35(2):68-77.

43. Schrimshaw EW, Siegel K, Wolfson NH, Mitchell DA, Kunzel C. Insurance-related barriers to accessing dental care among African American adults with oral health symptoms in Harlem, New York City. Am J Public Health. 2011;101(8):1420-1428.

44. Cashman SB, Savageau JA, Lemay CA, Ferguson W. Patient health status and appointment keeping in an urban community health center. J Health Care Poor Underserved. 2004;15(3):474-486. 